\title{
Influence of Exposure for Gamma and X-Ray Radiation on Bioglass Reparative Material Measured Using Two Techniques
}

\author{
Hany A. Shousha ${ }^{1}$, Fatma. M. El-Sharkawy ${ }^{2}$, Hany Kamal ${ }^{3} \&$ Nadia Rabie $^{4}$ \\ ${ }^{1}$ Department of Ionizing Radiation Metrology, National Institute for Standards (NIS), El-Haram El-Giza, Egypt \\ ${ }^{2}$ Department of Photometry, National Institute for Standards (NIS), El-Haram El-Giza, Egypt \\ ${ }^{3}$ Lecturer of biophysics - Physics Department, Faculty of Science, Mansoura University, Egypt \\ ${ }^{4}$ Department of Ionizing Radiation Metrology, National Institute for Standards (NIS), El-Haram El-Giza, Egypt \\ Correspondence: Hany A. Shousha, Department of Ionizing Radiation Metrology, National Institute for Standards \\ (NIS), El-Haram El-Giza PO Box 136 Giza, El-Giza, Egypt. E-mail: drshousha@yahoo.com
}

\author{
Received: May 21, 2012 Accepted: June 6, 2012 Online Published: July 15, 2012 \\ doi:10.5539/apr.v4n3p1 URL: http://dx.doi.org/10.5539/apr.v4n3p1
}

\begin{abstract}
Bioglass is a material which can repair damaged living tissues and organs by interacting with biological systems. Bioglass were irradiated by different beam qualities (gamma and X-ray). The effectiveness of different doses and energies of gamma ray and X-ray were studied on bioglass as well as some dosimetric properties of bioglass were studied by applying the thermoluminescence technique and spectrometer technique. Results showed that the efficiency of electron and hole center generation depends on basic bioglass composition and also dependent on the type of ionizing radiation. The response of dose is not effective at working voltage $70 \mathrm{kV}$ which means that the bioglass may be safe under this value of applied volt.
\end{abstract}

Keywords: Gamma ray, X-ray, bioglass, spectrophotometer, fading

\section{Introduction}

Historically the function of biomaterials has been to replace diseased or damaged tissues. First generation biomaterials were selected to be as bio-inert as possible and thereby minimize formation of scar tissue at the interface with host tissues.

The human body rejects metallic and synthetic polymer materials by forming scar tissue because living tissues are not composed of such materials. Bone contains a hydrated calcium phosphate component, hydroxyapatite [HA] and therefore if a material is able to form a HA layer in vivo it may not be rejected by the body (Hench, 2006).

Bioactive materials used for either tissue replacement or for tissue regeneration must possess controlled chemical release kinetics that synchronise with the sequence of cellular changes occurring in wound repair (Hench, 1998). If dissolution rates are too rapid the ionic concentrations are too high to be effective. Oonishi et al., 2000 and Wheeler et al., 2000 indicate that there are two classes of bioactive materials. Class A bioactivity leads to both osteoconduction and osteoproduction as a consequence of rapid reactions on the bioactive glass surface. Class $\mathrm{B}$ bioactivity occurs when only osteoconduction is present; i.e. bone migration along an interface, due to slower surface reactions, minimal ionic release and only extracellular responses occur at the interface (Hench, 1998). Differences between Class A and B bioactive materials are summarized in reference (Hench, 1998; Hench \& West, 1996).

Since the discovery of bioglass materials, many different applications for the use of these materials have been explored, including coatings of bioglass materials on devices for use in orthopedic, maxillofacial, middle ear and dental surgeries. Bioglass materials in powder or paste form also have a very large potential utility. Powders and pastes have found use in filling bony wounds as a putty, or through injection, whereas bulk bioglass materials usually require either clinical or preclinical shaping before surgical application (LeGeros, 1988).

The aim of this work is to study the physical characteristics of prepared bioglass samples usually used in reparation of human bones by using two techniques, thermoluminescence and spectrometer. Two sources were used (x-ray and gamma ray) for irradiating the samples to cover the energy range (70kv - 662kv), to conclude the 
effect of different energy on samples if peoples exposed to diagnostic or therapeutic ray.

\section{Materials and Methods}

\subsection{Bioglasses Preparation}

High purity silica, tellurium oxide, reagent-grade calcium carbonate, sodium carbonate and ammonium dihydrogen phosphate were used to obtain glass compositions. Raw materials were mixed and melted in alumina crucibles in an electric furnace at temperature range from $800{ }^{\circ} \mathrm{C}$ to $1400{ }^{\circ} \mathrm{C}$ for 1 hour. The melt was occasionally swirled to assure homogeneity and attainment of thermal and chemical equilibrium.

After refining, the melting glass was poured by pressing the sample between two ceramic plates to yield disc shaped samples. All samples prepared were homogenous, air bubbles-free and stored in desiccators for characterization. The glassy sample was then inserted directly into the furnace and held at the temperature of heat treatment for the desired time before cooling normally to room temperature. The samples were heat-treated at temperatures $620^{\circ} \mathrm{C}, 860{ }^{\circ} \mathrm{C}$ and $1000^{\circ} \mathrm{C}$ for time interval 10 hours. The average grain size of the various specimens was measured $\approx 60-90 \mu \mathrm{m}$ by Scanning Electron Microscope (SEM). The X-ray investigations were used to confirm the amorphous or crystalline nature of the structure.

\subsection{Irradiation Sources}

The irradiation of the pellets was performed using ${ }^{137} \mathrm{Cs}$ gamma source with dose rate $1.645 \mathrm{mGy} / \mathrm{min}$ at $300 \mathrm{~cm}$ have been measured using secondary standard dosimetry system where the combined uncertainty value is $1.75 \%$. The samples were irradiated at different gamma doses from 120.85 to $1450.2 \mathrm{~Gy}$

The X-ray machine used for irradiation in this study was of model MCN-323 metal-ceramic Philips double pole. The high voltage (HV) was directly measured by built in potential divider connected to the HV generator. The $\mathrm{HV}$ and tube current were adjusted in the range 15 to $320 \mathrm{kV}$ and 0 to $22.5 \mathrm{~mA}$, respectively. The setting needed for the X-ray tube according to TRS No. 469 of the International Atomic Energy Authority (IAEA, 2009).

The samples were irradiated for both medium X-ray at 100 and $135 \mathrm{kV}$ and low X-ray at $70 \mathrm{kV}$, according to CCRI (The Consultative Committee of Ionizing Radiation) (Liatano et al., 2005, Burns and Roger 2001).

\subsection{Thermoluminescence Technique}

TL measurements were made using Harshaw TL reader Model 4500. A heating rate of $5{ }^{\circ} \mathrm{C} / \mathrm{sec}$ was used to heat the samples from room temperature up to $400{ }^{\circ} \mathrm{C}$. The combined uncertainty value was calculated for the TLD samples were found to be $\pm 10.93 \%$.

\subsection{Spectrophotometer Technique}

The UV-Visible spectrophotometer were made using Shimadzu Model 3101PC. The surface were scanned at wavelengths from $200 \mathrm{~nm}$ to $3000 \mathrm{~nm}$ with the monochromator slit width at $5 \mathrm{~nm}$ and operated at a scan rate of $100 \mathrm{~nm} / \mathrm{min}$ to obtain maximum accuracy.

\section{Results}

\subsection{Optical Absorption Spectra}

The UV visible absorption spectra before and after irradiated to different gamma doses were studied for prepared bioactive glasses and shown in Figure 1.

The prepared bioglasses are colorless and reveal no characteristic band before irradiation. The samples were irradiated to gamma doses up to 1450.2 Gy and measured in the visible region showed an ultraviolet band at about $210 \mathrm{~nm}$ and this band is usually assigned to trace iron impurities in phosphate (Marzouk et al., 2011; Rai et al., 2011) and silicate (Khalil et al., 2010; Gusarov et al., 2010) glasses. On subjecting the glass to gamma irradiation, a shifting of the beginning of absorption to higher wavelength is observed with the resolution of a broad band extending from about 220 to $320 \mathrm{~nm}$ with a maximum depends on the gamma ray dose. With increasing g-doses, the intensity of the broad band increase accompanied with a progressive shifting of the beginning of absorption to higher wavelength.

The induced bands are observed to split to two absorption peak at 300 and $320 \mathrm{~nm}$ by high doses of gamma rays. Experimental results obtained in all bioglasses show almost an initial fast growth in the induced bands, reaching some sort of equilibrium or saturation condition as the dose rate is increased, where the ultraviolet bands are attributed to the electron surface. 


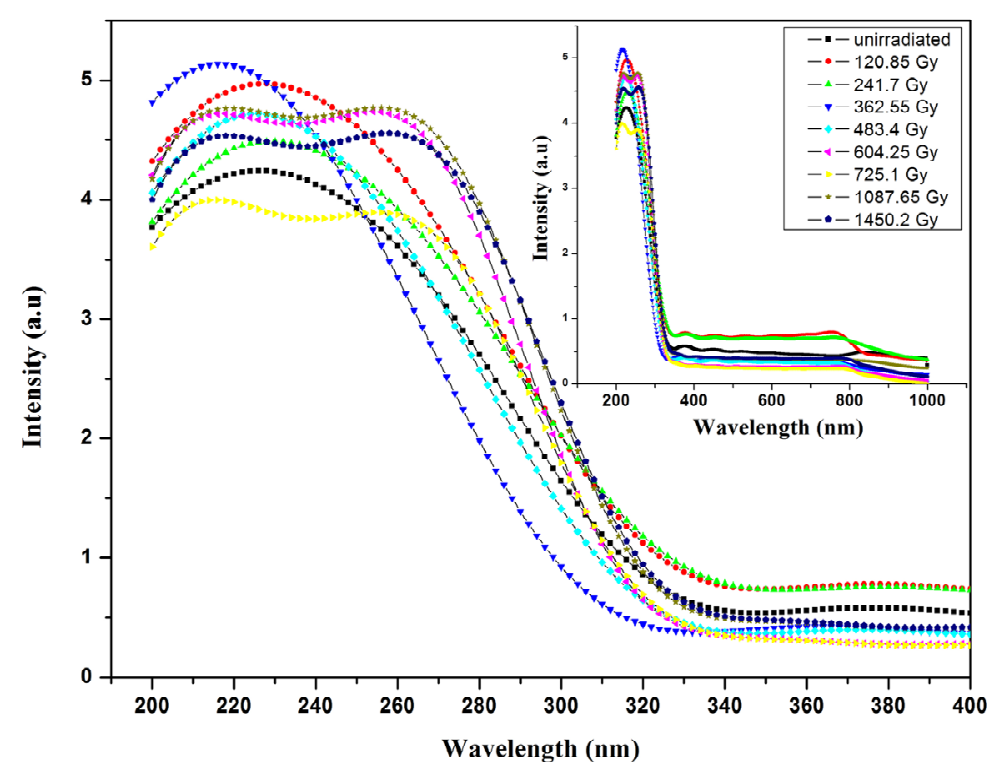

Figure 1. UV spectra for glassy samples after irradiation with different gamma doses

\section{$\mathrm{X}$-ray operating voltage at $70 \mathrm{KV}$}

The effect of X-ray irradiation on the absorption spectra of prepared glass samples are shown in Figure 2. The broad irradiation-induced absorption increment can be simulated by a superimposement of three Gaussian contours centered at 1.75, 3.04 and $4.29 \mathrm{eV}$. Such bands are known to appear in silicate glasses under UV, X-ray, gamma and electron irradiation and are attributed to color centers in glass (Gomonnai et al., 2001a).

It should be noted, when the glassy matrix irradiated to high X-ray doses the irradiation-induced blue shift of the absorption edge was observed to decrease slightly. As seen from Figure 3, for the most heavily irradiated samples to high working voltage $(100 \mathrm{kV})$ the absorption edge position shifts by $0.045 \mathrm{eV}$ for the high dose where the intensity (a.u) value arising than at low dose. Note that further irradiation dose results in no changes in the absorption spectrum. Such effect can be attributed to the post-irradiation relaxation which is generally typical for dielectric glass matrices (Gomonnai et al., 2001b).

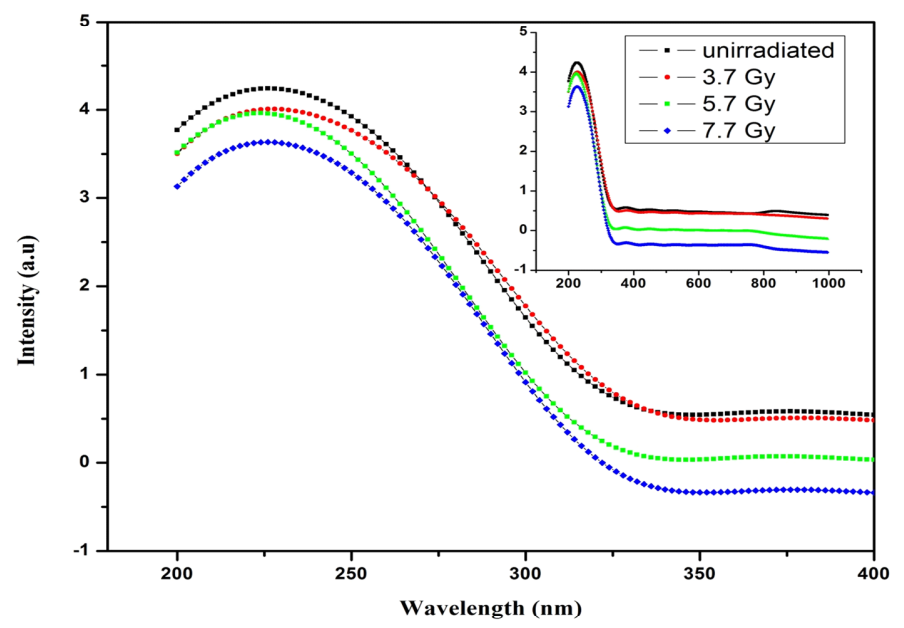

Figure 2. UV spectra for glassy samples before and after irradiation with different X-rays doses at operating voltage $70 \mathrm{kV}$ 


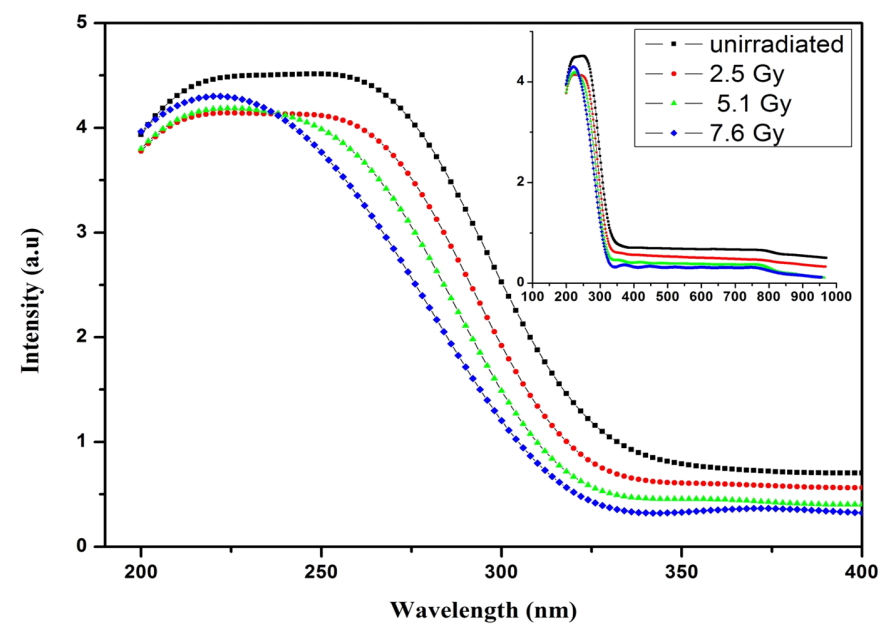

Figure 3. UV spectra for glassy samples before and after irradiation with different X-rays doses at operating voltage $100 \mathrm{kV}$

\section{X-ray operating voltage at $135 \mathrm{KV}$}

Generally, several factors can be responsible for the observed behavior of absorption spectra under X-ray irradiation. The gradual smearing of the observed bands, observed for all samples, can be attributed to the X-ray induced ionization due to electron (hole) transfer between the building units and irradiation-activated electron (hole) traps in the host matrix. With the increase of the irradiation dose the transferred charge-carriers occupy the confinement-related levels in the nanocrystals, gradually disabling the lower-energy transitions. Therefore, in glassy samples the irradiation-induced changes affect only the lower energy features. In this case the discussed effect results in the observed blue shift of the absorption edge.

Note that, a similar effect (the blue shift of the absorption edge) was observed in glasses under X-ray irradiation as in Figures 3 and 4. In both cases the blue shift is explained by photoionization process, the photoelectrons leaving the microcrystals and being captured by the traps in the glass. However, one should note that, the X-ray induced defects differs from the photo induced defects.

However, there are at least two more possible explanations for the absorption edge blue shift in the irradiated samples. At normal conditions, vibrational units in the glassy matrix already sustain hydrostatic pressure from the matrix. X-ray irradiation can result in the additional hydrostatic pressure due to the known phenomenon of radiation swelling of the glass matrix (Glebov et al., 1986). It should be also noted that, since the host glass matrix in contains a considerable amount of filler, the blue shift of the absorption edge can also be related to the incorporation of this filler into the glass structure through formation of non-bridging atoms.

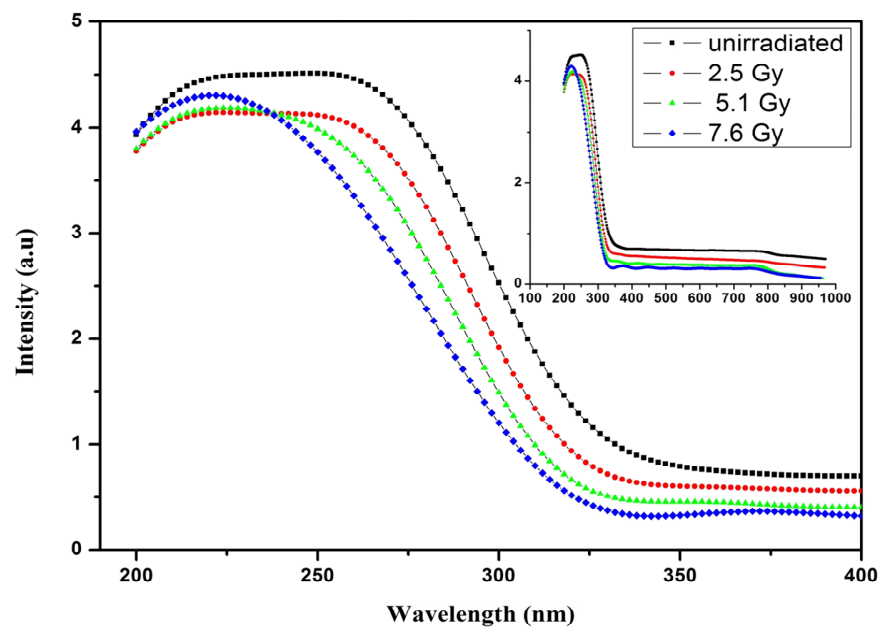

Figure 4. UV spectra for glassy samples before and after irradiation with different X-rays doses at operating voltage $135 \mathrm{kV}$ 


\subsection{Thermoluminescence Glow Curve}

The characteristic glow curves for glassy samples indicated single broadening glow peak, where the broadness of the peak may be as a result of the existence of closely spaced trapping center. The peak is very stable, and it remains in the same position independently of the radiation dose used gamma doses increase linearly with the TL-arbitrary unit.

The asymmetric and broadening of peak lead us to may use it in the monitoring to the TL response for glassy as in Figure 5 where represents TL-response for glassy samples before and after irradiation to different gamma doses from 120.85 to $1450.2 \mathrm{~Gy}$.

Figure 6 shows linearity rising TL response with increasing X- ray doses at different applied voltage 70, 100 and $135 \mathrm{kV}$. It was noticed that at working voltage $70 \mathrm{kV}$ the response effect is negative value less than 2 Gy which means that the bioglass may be safe under this value of applied volt. But at $135 \mathrm{kV}$ the response dose more than 0.5 Gy effect on bioglass and may be make fragile.

Figure 7 shows the integrated TL-intensity after storage period of two weeks at room temperature. It was noticed that the fading is very high dropping equal 3\% through 14 days which indicate that the bioglass doesn't keep the exposure dose.

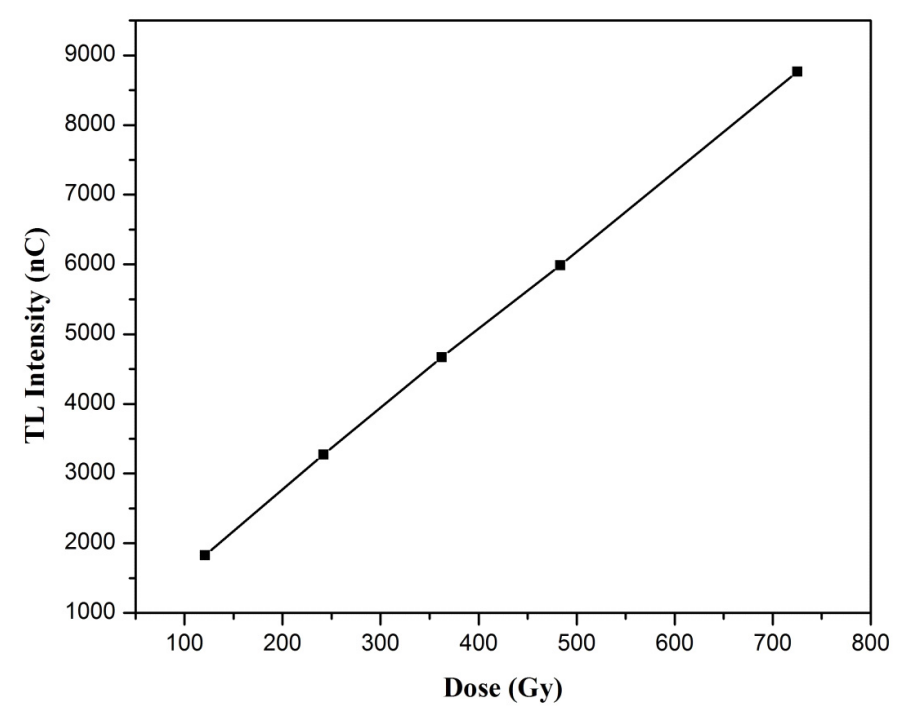

Figure 5. TL-response curve for glassy samples irradiated to different gamma doses from 120.85 to $1450.2 \mathrm{~Gy}$

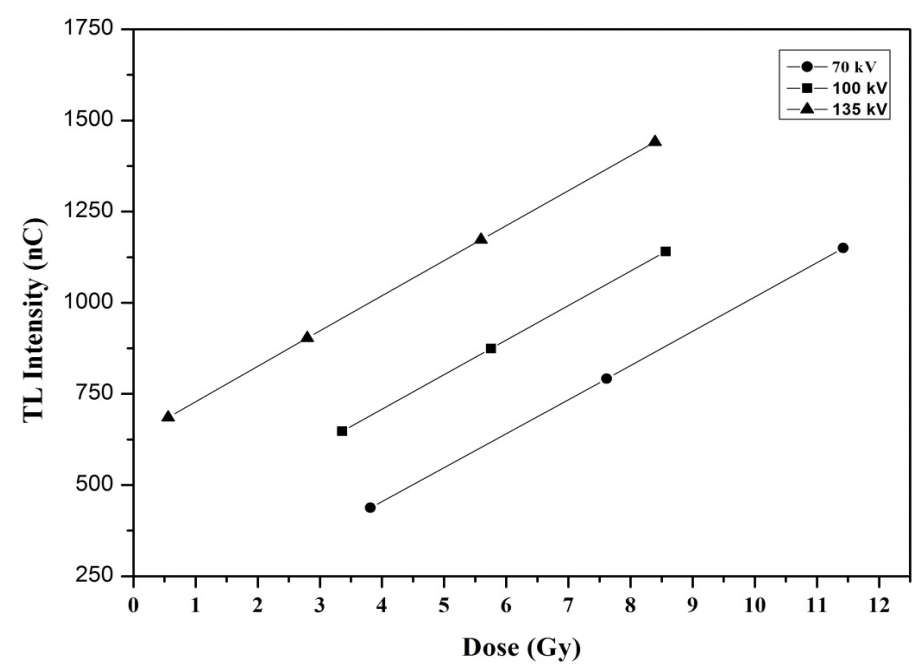

Figure 6. TL-response curves for glassy samples irradiated to different X-ray doses from 0.5 to 11.5 Gy at operating voltage 70,100 and $135 \mathrm{kV}$ 


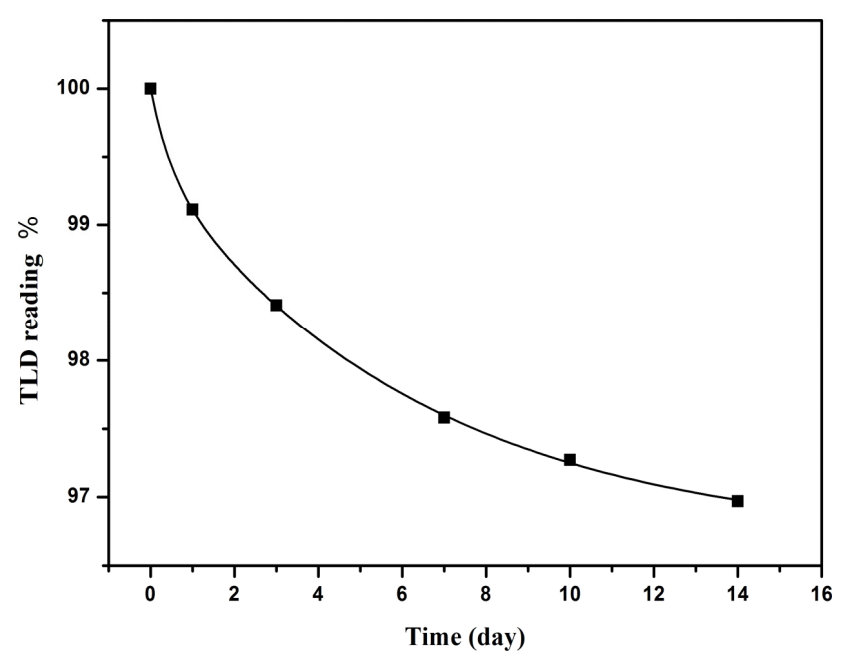

Figure 7. Fading by (day) viruses the relative unit for TL-output (nC) for glassy samples

\section{Conclusions}

The influence of different doses of X-ray and gamma ray were studied for bioglass used as a reparative material which can repair damaged living tissues and organs. The response of different doses of X-ray and gamma ray on bioglass samples gives a straight line. The dose is not effective at working voltage $70 \mathrm{kV}$ which means that the bioglass may be safe under this value of applied volt. But at $135 \mathrm{kV}$ the response dose more than 0.5 Gy effect on bioglass and makes it fragile. Fading studied indicated that the bioglass rapidly loss the exposure dose.

\section{Reference}

Burns, D. T., \& Roger, P. (2001). Characterization of the BIPM low-energy xray facility following a change of $\mathrm{x}$-ray tube and high-voltage generator, $\mathrm{CCRI}(\mathrm{I}) / 01-07$.

Glebov, L. B., Dokuchayev, V. G., Nikonorov, N. V., \& Petrovskii, G. T. (1986). Change in the Volume of Glass After Low-Temperature Ion Echange. Fiz. Khim. Stekla Translation, 14(2), pp 232-239, March-April 1988. Original article: 12(3), 345-361, 1986.

Gomonnai, A. V., Azhniuk, Yu. M., Goyer, D. B., Megela, I. G., \& Lopushansky, V. V. (2001a). Optical studies of alkali borosilicate glass irradiated with high-energy electrons. Journal of Optoelectronics and Advanced Materials, 3(1), 37-44.

Gomonnai, A. V., Solomon, A. M., Azhniuk, Yu. M., Kranjčec, M., Lopushansky, V. V., Megela, I. G. (2001b). $\mathrm{X}$-ray excited luminescence and X-ray irradiation effect on CdS1-xSex nanocrystas optical absorption. Journal of Optoelectronics and Advanced Materials, 3(2), 509-514.

Gusarov, A., Huysmans, S., Berghmans, F., Glebova, L., Glebov, L., \& Hodgson, E. R. (2010). Induced optical absorption of silicate glasses due to gamma irradiation at high temperatures. J. Fusion Engineering. Design, $85(1), 1-6$.

Hench, L. L. (1998). Bioceramics. J. Am. Ceram. Soc., 81(7), 1705 . http://dx.doi.org/10.1007/s10856-006-0432-z

Hench, L. L. (2006). The story of Bioglass. J. Mater. Sci. Mater. Med., 17, 967-978. http://dx.doi.org/10.1007/s10856-006-0432-z

Hench, L. L., \& West J. K. (1996). Biological applications of bioactive glasses. Life Chem. Rep., 13, 187-241.

IAEA. (2009). International Atomic Energy Agency, Technician report series (TRS) No. 469, calibration of reference dosimeters for external beam radiotherapy.

Khalil, E. M. A., El-Batal, F. H., Hamdy, Y. M., Zidan, H. M., Aziz M. S., Abdelghany, A. M. (2010). FTIR Spectral Analysis of Corrosion Mechanisms in Soda Lime Silica Glasses Doped with Transition Metal Oxides. J. Silicon, 2(1), 49-60. http://dx.doi.org/10.1007/s12633-009-9029-8

LeGeros, R. Z. (1988). Calcium Phosphate materials in restorative dentistry: a review. Adv. Dental Res., 2(1), 
164-180.

Liatano, R. F., Pimpinella, M., Toni, M. P., \& Casaccia, C. R. (2005). Redetermination of $\mathrm{K}_{\mathrm{sc}}, \mathrm{K}_{\mathrm{e}}, \mathrm{K}_{\mathrm{fl}}$ correction factors for low and medium" KERMA measurement by the ENEA-INMRI free-air chamber., (CCRI)(I)-05-31 (2005).

Marzouk, M. A., ElBatal, H. A., Abdel Ghany, A. M., \& Ezz Eldin, F. M. (2011). Ultraviolet, visible, ESR, and infrared spectroscopic studies of CeO2-doped lithium phosphate glasses and effect of gamma irradiation. $J$. of Molec. Struc. 997(1-3), 94-102. http://dx.doi.org/10.1016/j.molstruc.2011.05.004

Oonishi, H., Hench, L. L., Wilson, J., Sugihara, F., Tsuji, E., Matsuwura, M., ... Mizokawa S. (2000). Quantitative comparison of bone growth behavior in granules of Bioglass ${ }^{\circledR}, \mathrm{A}-\mathrm{W}$ glass-ceramic, and $\begin{array}{lllll}\text { hydroxyapatite. } \quad \text { B } & \text { Biomed. } & \text { Res., } & \text { 37-46. }\end{array}$ http://dx.doi.org/10.1002/(SICI)1097-4636(200007)51:1\%3C37::AID-JBM6\%3E3.0.CO;2-T

Rai, V. N., Raja Sekhar, B. N., Tiwari, P., Kshirsagar, R. J., \& Deb, S. K. (2011). Spectroscopic studies of gamma irradiated $\mathrm{Nd}$ doped phosphate glasses. J. of Non-Crystalline Solids, 357(22), 3757-3764. http://dx.doi.org/10.1016/j.jnoncrysol.2011.07.036

Wheeler, D. L., Eschbach, E. J., Hoellrich, R. G., Montfort, M. J., \& Chamberland, D. L. (2000). Assessment of resorbable bioactive material for grafting of critical-size cancellous defects. J. Orthop. Res., 18(1), $140-148$. http://dx.doi.org/10.1002/jor.1100180120 